Check for updates

Cite this: RSC Adv., 2019, 9, 21000

Received 19th February 2019

Accepted 26th June 2019

DOI: 10.1039/c9ra01257e

rsc.li/rsc-advances

\section{Kinetic studies of few-layer graphene grown by flame deposition from the perspective of gas composition and temperature $\uparrow$}

\author{
Edhuan Ismail, (D) a Fatin Bazilah Fauzi, (D) ${ }^{a}$ Mohd Ambri Mohamed, ${ }^{\mathrm{b}}$ \\ Mohd Fairus Mohd Yasin, (D) C Mohd Asyadi Azam Mohd Abid, ${ }^{d}$ Iskandar Idris Yaacob, ${ }^{a}$ \\ Muhamad Faiz Md Din ${ }^{\mathrm{e}}$ and Mohd Hanafi Ani ${ }^{\star a}$
}

\begin{abstract}
Studies on depositions of chemical vapour deposition (CVD) diamond films have shown that flame combustion has the highest deposition rates without involving microwave plasma and direct current arc. Thus, here we report on our study of few-layer graphene grown by flame deposition. A horizontal CVD reactor was modified for the synthesis of flame deposition of few-layer graphene on a Cu substrate. It was found that graphene obtained has comparable quality to that obtained with other flame deposition setups reported in the literature as determined from Raman spectroscopy, sheet resistance, and transmission electron microscopy. Calculation of the chemical kinetics reveals a gas phase species that has a close correlation to the growth rate of graphene. This was further correlated with van't Hoff analysis of the reaction, which shows that the growth reaction has a single dominating mechanism for temperatures in the range of $400{ }^{\circ} \mathrm{C}$ to $1000{ }^{\circ} \mathrm{C}$. Arrhenius analysis also was found to be in good agreement with this result. This study shows few-layer graphene growth proceeds through different pathways from a CVD grown graphene and also highlights flame deposition as a viable method for graphene growth.
\end{abstract}

\section{Introduction}

Current production of high-quality large-area graphene can only be achieved through chemical vapour deposition. No other method comes close to producing the quality of graphene produced by this method. ${ }^{1}$ However, some significant barriers remain for the widespread production of graphene by this method. One of them is that due to its batch production coupled with long reaction times at high temperatures, CVD becomes a very energy intensive method equating to increased costs. Through this method, graphene with resistivity as low as $143 \Omega \mathrm{cm}$ has been achieved. ${ }^{2}$ Bae et al. ${ }^{3}$ growing graphene films reports a sheet resistance of $30 \Omega$ per square. In comparison,

${ }^{a}$ Department of Manufacturing and Materials, Kulliyyah of Engineering, International Islamic University Malaysia, P. O. Box 10, 50728 Kuala Lumpur, Malaysia. E-mail: mhanafi@iium.edu.my

${ }^{b}$ Institute of Microengineering and Nanoelectronic, Universiti Kebangsaan Malaysia, 43600 Bangi, Malaysia

${ }^{c}$ High Speed Reacting Flow Laboratory (HiREF), Universiti Teknologi Malaysia, 81310 Johor Bahru, Malaysia

${ }^{d}$ Faculty of Manufacturing Engineering, Universiti Teknikal Malaysia Melaka (UTeM), Hang Tuah Jaya, Durian Tunggal, 76100 Melaka, Malaysia

${ }^{e}$ Department of Electrical and Electronic, Faculty of Engineering, National Defence University of Malaysia, Kem Sungai Besi, Kuala Lumpur, Malaysia

$\dagger$ Electronic supplementary information (ESI) available. See DOI: 10.1039/c9ra01257e pristine graphene obtained from exfoliation of graphite has $10^{-6} \Omega \mathrm{cm}$ resistivity ${ }^{4}$ with a maximum current density ${ }^{5}$ larger than $10^{8} \mathrm{~A} \mathrm{~cm}^{-2}$.

So far, much progress has been made to reduce its energy consumption through the development of better catalysts and growth methods. In general, copper has been the choice substrate for graphene growth due to its wide availability. When compared to other elements, it is cheaper compared to other metals but its high energy barrier creates a need for high reaction temperatures for graphene to grow. ${ }^{6}$ Most recently, gallium and cobalt-copper alloy substrates were shown to grow graphene at lower temperatures. ${ }^{7,8}$

While such catalytic substrates could potentially reduce the reaction temperature and improve reaction rate, there is still a need for better production methods as it will ultimately determine the scale of which graphene can be produced. For now, modifications to the conventional CVD methods have been shown to allow good quality graphene to be produced at even lower temperatures. Usage of plasma has been widely reported to have reduced the growth temperatures of graphene and commercially manufactured reactors are already available for plasma enhanced CVD (PECVD). Instead of thermally activating the reactants within the gas phase or on the substrate, reactants are first turned to active species within the plasma itself. As a result, growth temperature could be lowered as low as $<420{ }^{\circ} \mathrm{C}$ while maintaining a high-quality growth., ${ }^{9,10}$ 
However, the need for a high-power plasma generator and a good vacuum system makes the setup very complex and has high energy consumption. Thus, graphene grown by this method is very expensive due to its batch production capabilities and very strict control of the growth conditions.

Here, we explore an alternative way which could emulate plasma enhanced CVD using flame deposition. Historically, deposition of diamond by flame combustion have been widely studied and it has been shown to have a very high deposition rate when compared to other methods except for direct current arc. ${ }^{11}$ Previous to graphene synthesis by flame deposition, Wal et al. reports of the growth of carbon nanotubes by flame deposition only requiring reaction times in the order of milliseconds. ${ }^{12}$ The combustion itself raises the temperature allowing the remaining hydrocarbons to form the desired product. One of the earliest reports of graphene grown by flame deposition used a dual flame setup. ${ }^{\mathbf{1 3 , 1 4}}$ Nickel substrate was kept within a flame sheath to prevent oxidation while another carburizing flame heats and provides carbon to the substrate. The authors reported that graphene synthesized through this method did not have full coverage and contains many defects. Another group built a micro combustor for the flame deposition of graphene on $\mathrm{Cu}$ and $\mathrm{Ni}$ wires where they found high Reynolds number yields better graphene qualities. ${ }^{15} \mathrm{~A}$ setup developed by Memon et al. ${ }^{16}$ for large area graphene growth used an inverse diffusion flame. The inverse diffusion flame getters excess $\mathrm{O}_{2}$ and provides a stable flame. They reported a graphene deposit which has a monolayer ratio $\left(I_{2 \mathrm{D}} / I_{\mathrm{G}}\right)$ of 0.77 to 0.59 and defect ratio $\left(I_{\mathrm{D}} / I_{\mathrm{G}}\right)$ of 0.35 grown at $1000{ }^{\circ} \mathrm{C}$ for 10 minutes. Our group have also reported on achieving similar quality graphene using a horizontal CVD reactor modified for flame deposition. ${ }^{17}$ This highlights the potential that this method possesses for producing graphene at lowered temperatures.

While there are many discussions on the growth mechanism for CVD grown graphene, ${ }^{18}$ there are no known studies relating to growth mechanisms for graphene grown by flame deposition. However, combustion reactions of hydrocarbon have been studied in relation to diamond film formation. ${ }^{19,20}$ In fact, there are various models that have been built which even allows predictions of the resulting equilibrium species. In this study, we aim to study the growth kinetics of graphene grown on $\mathrm{Cu}$ substrate using a flame deposition method. Complimenting the experimental results are simulations of equilibrium species based upon a soot production model. ${ }^{21}$

\section{Experimental}

\section{Deposition}

Graphene was grown using a homemade horizontal hot-wall furnace fitted with a ceramic nozzle to allow combustion. The furnace core is a ceramic tube wrapped with Kanthal wires and insulated with ceramic fibres (Isowool, Isolite Insulating Products Co. Ltd.). An ignition system was attached to the nozzle to initiate combustion as shown in Fig. 1. A quartz tube was used as the reactor tube fitted with glass flanges at the ends. Oxygen $\left(\mathrm{O}_{2}\right)$ gas enters from the ceramic nozzle to mix with methane $\left(\mathrm{CH}_{4}\right)$ and hydrogen $\left(\mathrm{H}_{2}\right)$ gas entering from a separate ingress. 2
R-type thermocouples were used to regulate and observe the temperature. One was placed with the substrate and another outside of the quartz tube within the isothermal region.

Substrate preparation before the deposition is as follows. A copper foil (0.15 mm, Magna Value Sdn. Bhd.) was polished and cleaned thoroughly before use. First, various grits of sandpaper were used until reaching \#2000 grit. Next, alumina polish (1micron MicroPolish Alumina; Buehler) was used as the final finishing before cleaning with acetone (AR grade; R\&M Chemicals) followed by distilled water in an ultrasonic bath for 30 minutes. Once done, it was dried thoroughly and stored in a dry place. For the deposition, the foils were cut into $1 \mathrm{~cm}$ by $1.5 \mathrm{~cm}$.

Before deposition, an annealing step was performed at $1000{ }^{\circ} \mathrm{C}$ for 20 minutes in a $\mathrm{H}_{2}$ atmosphere with a flow rate of $100 \mathrm{sccm}$. It was then removed from the furnace hot-zone and allowed to cool under Ar gas flow till room temperature. Once cooled, the substrate with Ar gas, $\mathrm{CH}_{4}$ and $\mathrm{H}_{2}$ were introduced followed by $\mathrm{O}_{2}$ gas. Upon introducing $\mathrm{O}_{2}$ gas, flame ignition was initiated, and the substrate was inserted back into the heated furnace at a temperature of $1000{ }^{\circ} \mathrm{C}$ for graphene deposition. After 10 minutes deposition, the substrate was taken out from the hot-zone and allowed to cool to room temperature in an $\mathrm{Ar}$ atmosphere. The whole reaction takes place at atmospheric pressure and its overall procedure is shown in Fig. 2.

3 parameters were tested, which are partial pressures of $\mathrm{CH}_{4}$, $\mathrm{O}_{2}$, and $\mathrm{H}_{2}$. Partial pressure for each reactant was changed while keeping the remaining 2 reactants at the same ratio to each other. Graphene deposits obtained were transferred and characterized.

\section{Transfer and characterization}

Graphene deposits on $\mathrm{Cu}$ substrate were transferred using methyl methacrylate found commonly in super glue with tissue fibres as a reinforcing matrix. Sheet resistance measurements were done on these transferred deposits using a 4-point colinear probe with a potentiostat (Autolab PGSTAT302N, Metrohm). Sheet resistance, $R_{\mathrm{S}}$ was then converted to deposit thickness, $t$ by the following eqn (1) where graphite resistivity ( $\rho$ $=4 \times 10^{-5} \Omega \mathrm{cm}$ ) was used.

$$
R_{\mathrm{s}}=\frac{\rho}{t}
$$

Additionally, graphene was also transferred to a silicon wafer and copper mesh grid (\#300 CU TEM, U1017-5NM; EM Japan Co., Ltd.) for analysis by Raman spectroscopy (532 nm, inVia

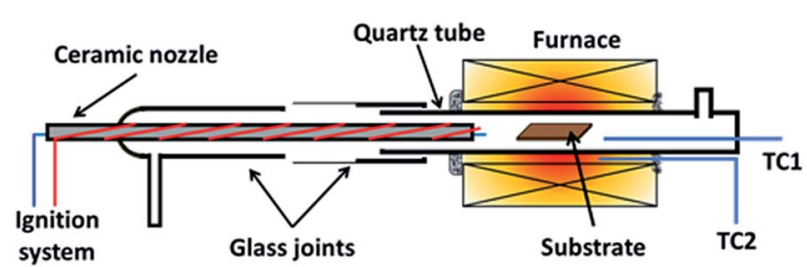

Fig. 1 Illustration of reactor used for flame deposition made from a quartz tube with glass flanges with a ceramic nozzle. 


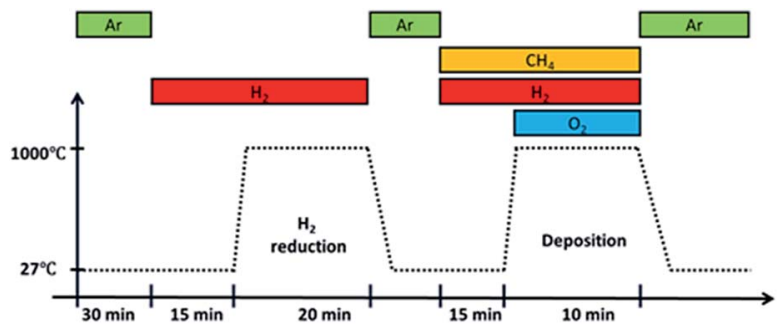

Fig. 2 Overall procedure of growth by flame deposition. Ignition occurs upon introducing $\mathrm{O}_{2}$ gas into the system.

Renishaw) and transmission electron microscopy (TEM) (120 kV Talos L120C; Thermo Fischer Scientific). Fast Fourier Transform analysis was also done on bright field images from TEM using FIJI software. ${ }^{22}$

\section{Computational analysis}

Apart from experimental data, numerical analysis of the concentrations of equilibrium species was also done using Cantera $^{23}$ set to conditions similar to those stated in the experiments using a mechanism file containing 296 species. ${ }^{21}$

\section{Result and discussion}

\section{Graphene deposition}

Deposit thickness calculated from the measured sheet resistance is shown in Fig. 3. From Fig. 3(a) changes in $\mathrm{CH}_{4}$ partial pressure, $P\left(\mathrm{CH}_{4}\right)$ while $\mathrm{H}_{2} / \mathrm{O}_{2}$ ratio was set to unity results in thicker deposit as $P\left(\mathrm{CH}_{4}\right)$ increases. However, deposit thickness reaches a maximum between 0.6 and $0.8 \mathrm{~atm} P\left(\mathrm{CH}_{4}\right)$. For the dependency of $P\left(\mathrm{O}_{2}\right)$, while $\mathrm{CH}_{4} / \mathrm{H}_{2}$ is set to unity, deposit thickness reaches a maximum at $P\left(\mathrm{O}_{2}\right)=0.2$ atm before decreasing again as seen in Fig. 3(b). In Fig. 3(c) it can be seen that deposit thickness increases with higher $P\left(\mathrm{H}_{2}\right)$. However, it should be noted that the increase in deposit thickness due to $P\left(\mathrm{H}_{2}\right)$ is very small when compared to changes due to $P\left(\mathrm{CH}_{4}\right)$ and $P\left(\mathrm{O}_{2}\right)$. For $P\left(\mathrm{H}_{2}\right)$ deposit thickness increased from $0.5 \AA$ to $2.1 \AA$ whereas, graphene thickness increased by 100 fold for $P\left(\mathrm{CH}_{4}\right)$ and 10 fold for $P\left(\mathrm{O}_{2}\right)$. In general, conditions that yields thin deposits have a larger deviation which gets smaller as the

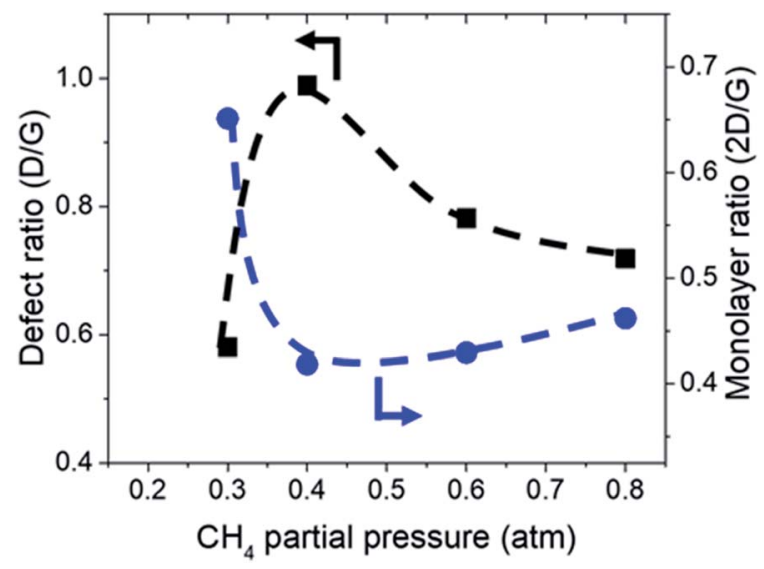

Fig. 4 Defect ratio $\left(/_{\mathrm{D}} / /_{\mathrm{G}}\right)$ and monolayer ratio $\left(/_{2 \mathrm{D}} / /_{\mathrm{G}}\right)$ of graphene deposited with varying $\mathrm{CH}_{4}$ partial pressure at $1000{ }^{\circ} \mathrm{C}$ for 10 minutes.

deposits get thicker. Unsurprisingly, thinner deposits are harder to reproduce as any slight changes induces a significant change in thickness. This is clearly demonstrated in Fig. 3(a) where the error bars get smaller with thicker deposit. Since deposit obtained in Fig. 3(b) and (c) are relatively thin, deviations within the deposit thickness against partial pressure is not clear.

For Fig. 3(a), at lower $P\left(\mathrm{CH}_{4}\right)$, the low initial $P\left(\mathrm{CH}_{4}\right)$ coupled with high $P\left(\mathrm{O}_{2}\right)$ leaves only a small amount of unreacted hydrocarbon to serve as the precursor for graphene. As it increases, there are more excess hydrocarbon allowing for thicker deposits. In Fig. 3(b) where $P\left(\mathrm{O}_{2}\right)$ was varied, even a small addition of $\mathrm{O}_{2}$ was found to promote thicker deposits until a certain threshold which is in line with reported observations. ${ }^{24}$ It was noted that $\mathrm{O}_{2}$ was found to assist in the pyrolysis of $\mathrm{CH}_{4}$ which improves growth rate but higher $P\left(\mathrm{O}_{2}\right)$ instead oxidizes and depletes aromatic hydrocarbons vital for the production of solid carbons.

Additionally, Raman characterization of deposits for the dependency on $\mathrm{CH}_{4}$ partial pressure was done and TEM analysis was performed on the deposit grown at $\mathrm{CH}_{4}: \mathrm{O}_{2}: \mathrm{H}_{2}=$ $0.8: 0.1: 0.1 \mathrm{~atm}$ which is shown in Fig. 4 and 5 . Defect ratio $\left(I_{\mathrm{D}} / I_{\mathrm{G}}\right)$ and monolayer ratio $\left(I_{2 \mathrm{D}} / I_{\mathrm{G}}\right)$ in Fig. 4 shows that higher
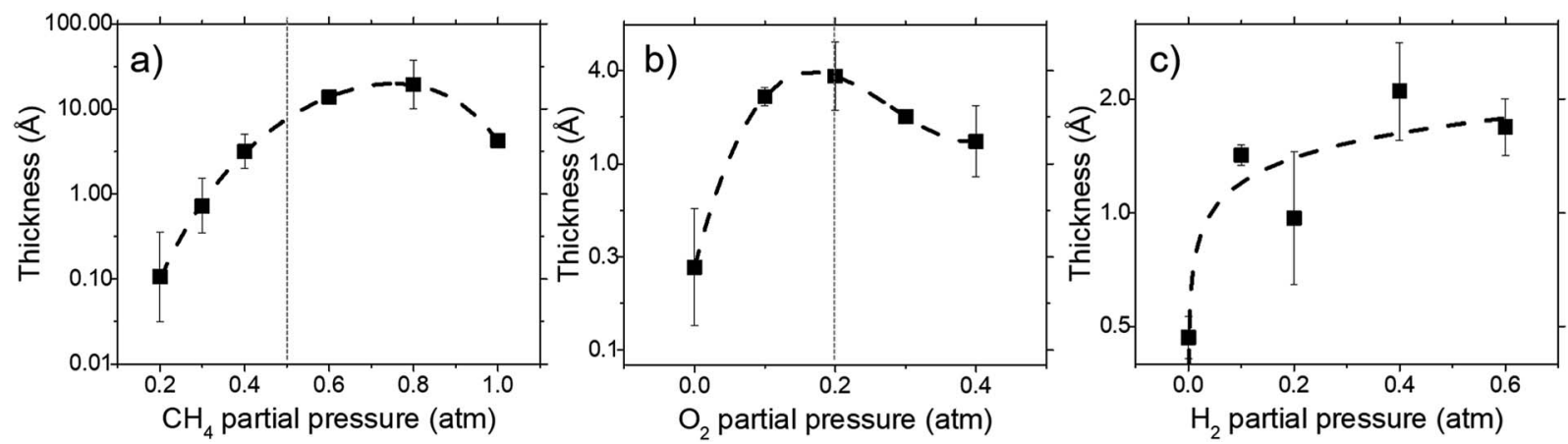

Fig. 3 The effect of (a) $\mathrm{CH}_{4}$, (b) $\mathrm{O}_{2}$, and (c) $\mathrm{H}_{2}$ partial pressure on deposit thickness as measured by sheet resistance for a reaction at $1000{ }^{\circ} \mathrm{C}$ for 10 minutes. All cases maintain the remaining 2 reactant that at equal ratio to each other. 
a)

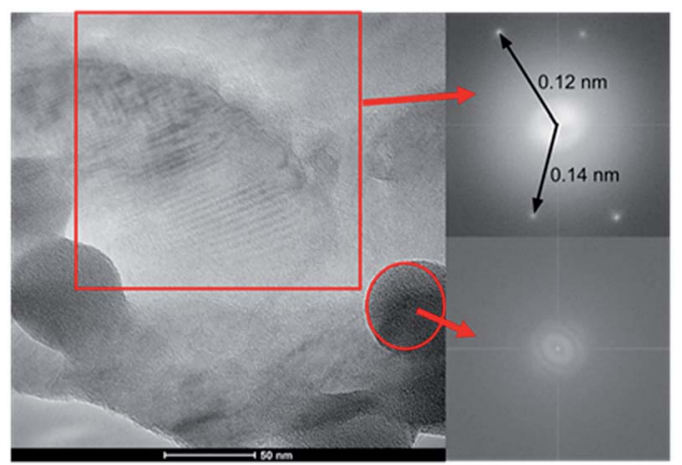

b)

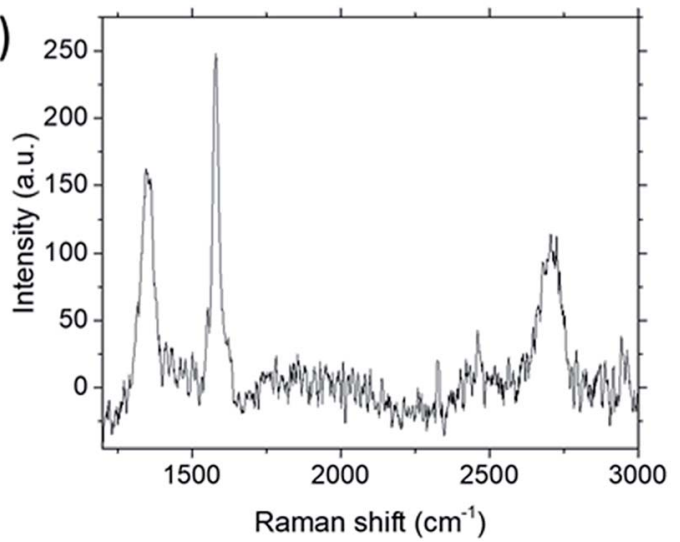

Fig. 5 (a) TEM characterization of graphene deposited at $\mathrm{CH}_{4}: \mathrm{O}_{2}-$ $: \mathrm{H}_{2}=0.8: 0.1: 0.1$ grown at $1000^{\circ} \mathrm{C}$ for 10 minutes. Inset shows FFT analysis for the highlighted regions within the image. (b) Raman spectra for the deposit.

$P\left(\mathrm{CH}_{4}\right)$ yield deposits that are higher in defects and thicker which is in good agreement with thickness calculated from sheet resistance Fig. 3(a). Thus, good quality graphene could be obtained but at the cost of higher $P\left(\mathrm{CH}_{4}\right)$. Again, a transition point was observed at the $0.4 \mathrm{~atm}$ to $0.5 \mathrm{~atm}$ range similar to the one in sheet resistance where thickness growth rate undergoes a change. Growth rate slows down beyond this point as $\mathrm{O}_{2}$ and
$\mathrm{H}_{2}$ get further diluted by $\mathrm{CH}_{4}$ which hints of an optimal $\mathrm{O}_{2}$ and $\mathrm{H}_{2}$ composition in aiding the growth of graphene.

TEM analysis of the deposit reveals the presence of graphene structures and amorphous carbon. Fast Fourier Transformation (FFT) of a region with moiré pattern in Fig. 5(a) shows that it has a lattice constant of 1.2-1.4 $\AA$ which originated from the lattice of graphene. ${ }^{25}$ Observing another region with spherical carbon nodules yields an FFT image with rings and devoid of any spots. Raman spectra of the same deposit in Fig. 5(b) shows defect ratio higher than 0.6 and monolayer ratio of about 0.5 . Several additional weak peaks were also observed. The peak at $2325 \mathrm{~cm}^{-1}$ was detected even on blank $\mathrm{Cu}$ (Fig. S1†) without graphene deposit leading us to conclude it is not carbon related. Peaks at $2640 \mathrm{~cm}^{-1}$ and $2946 \mathrm{~cm}^{-1}$ have been identified as an overtone to fundamental modes as was determined by Raman spectroscopy of highly ordered pyrolyzed graphite. ${ }^{26}$ Observations of deposits grown at other $P\left(\mathrm{CH}_{4}\right)$ values also shows fewlayer graphene as observed by Raman analysis in Fig. 4. Thus, it can be concluded that graphitic and amorphous carbon are both present in the deposit.

Analysis of diffraction patterns of the bright spots in Fig. 6(a) and (b) shows a 6-fold symmetry. However, the angles between some spots deviate from the typical $60^{\circ}$ which suggest the presence of differently oriented lattice. The presence of many diffraction spots forming a ring suggests the polycrystalline nature of the graphene deposited. 4 bright diffraction spots were observed in Fig. 6(b) which might be due to the uneven deposit surface. The corresponding lattice spacing calculated from these reciprocal lattices were approximately $0.12 \mathrm{~nm}$. This value fits with the $0.12 \mathrm{~nm}$ obtained from FFT images which corresponds to the graphene's lattice spacing of $0.121 \mathrm{~nm}$. In Fig. 6(c), another lattice constant of $0.099 \mathrm{~nm}$ was also observed, probably due to the presence of diamond-like carbons. ${ }^{27}$ The absence of $d=0.213 \mathrm{~nm}$ diffraction spots by graphene indicates that the deposit is few-layer graphene. ${ }^{25}$ Transferring the graphene on a $\mathrm{Cu}$ mesh introduces additional crumples and folds which will lead to regions of multilayered polycrystalline graphene which could be concluded from the twisted diffraction rings. Such defects are not originally present on the deposit
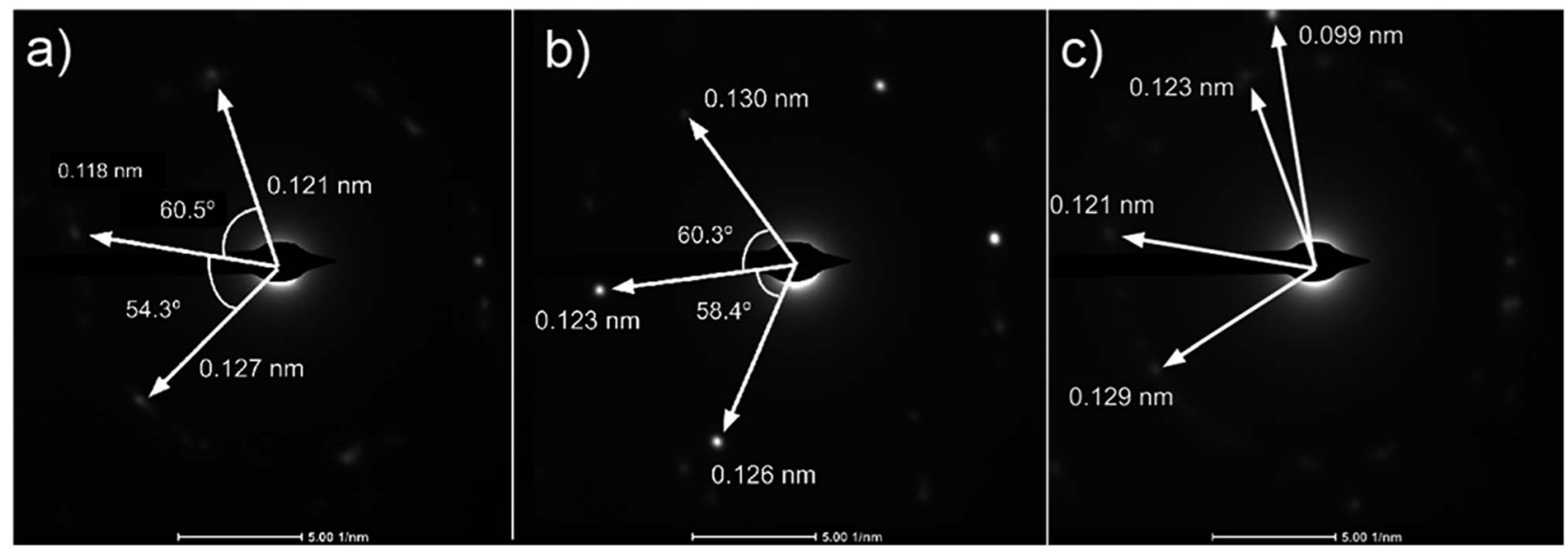

Fig. 6 (a)-(c) Diffraction patterns from several spots of graphene deposited using $\mathrm{CH}_{4}: \mathrm{O}_{2}: \mathrm{H}_{2}=0.8: 0.1: 0.1$ at $1000{ }^{\circ} \mathrm{C}$ for 10 minutes. 
a)
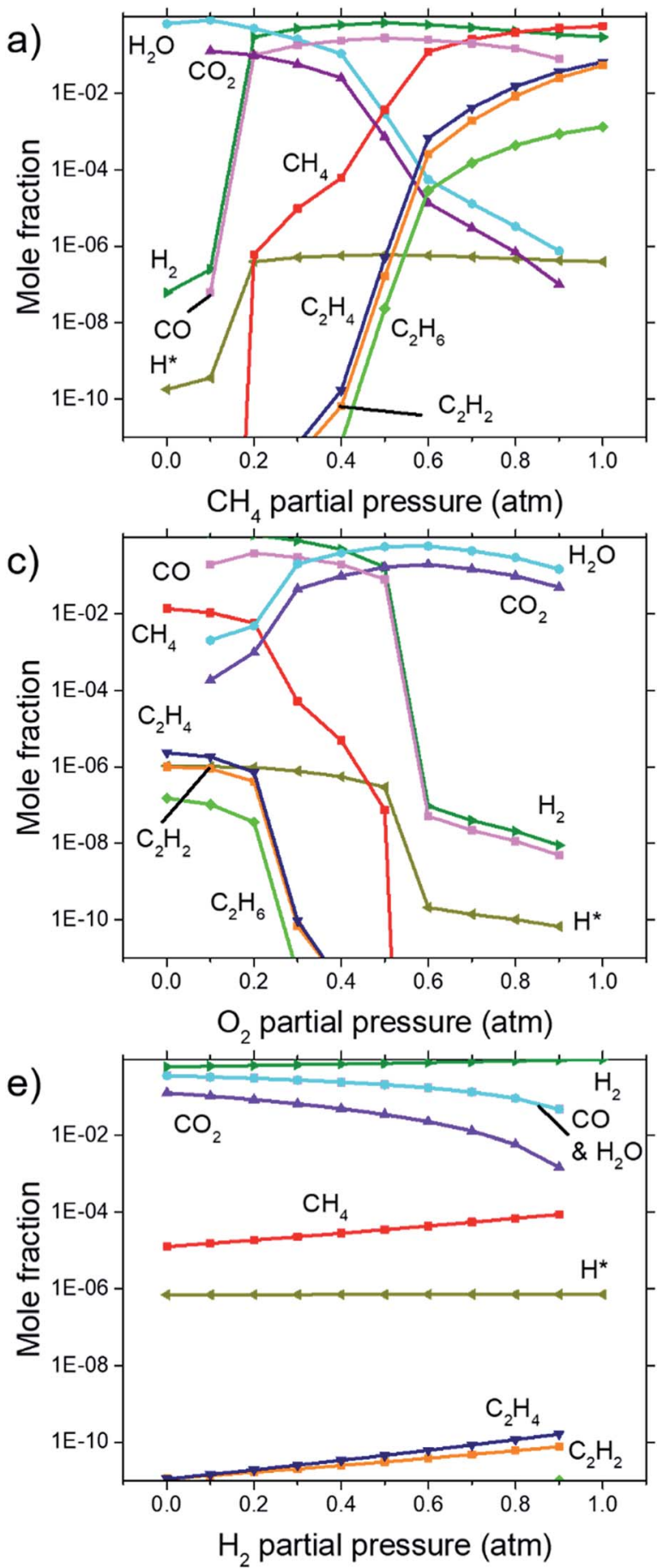

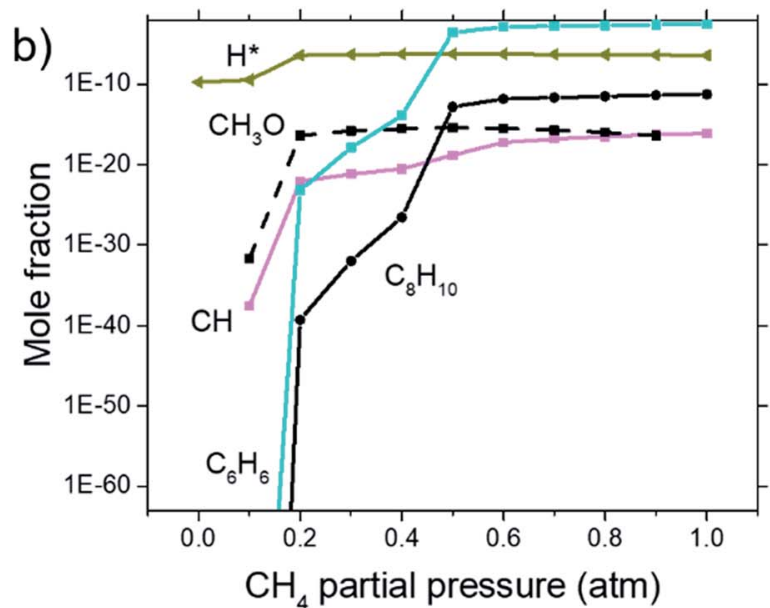

d)
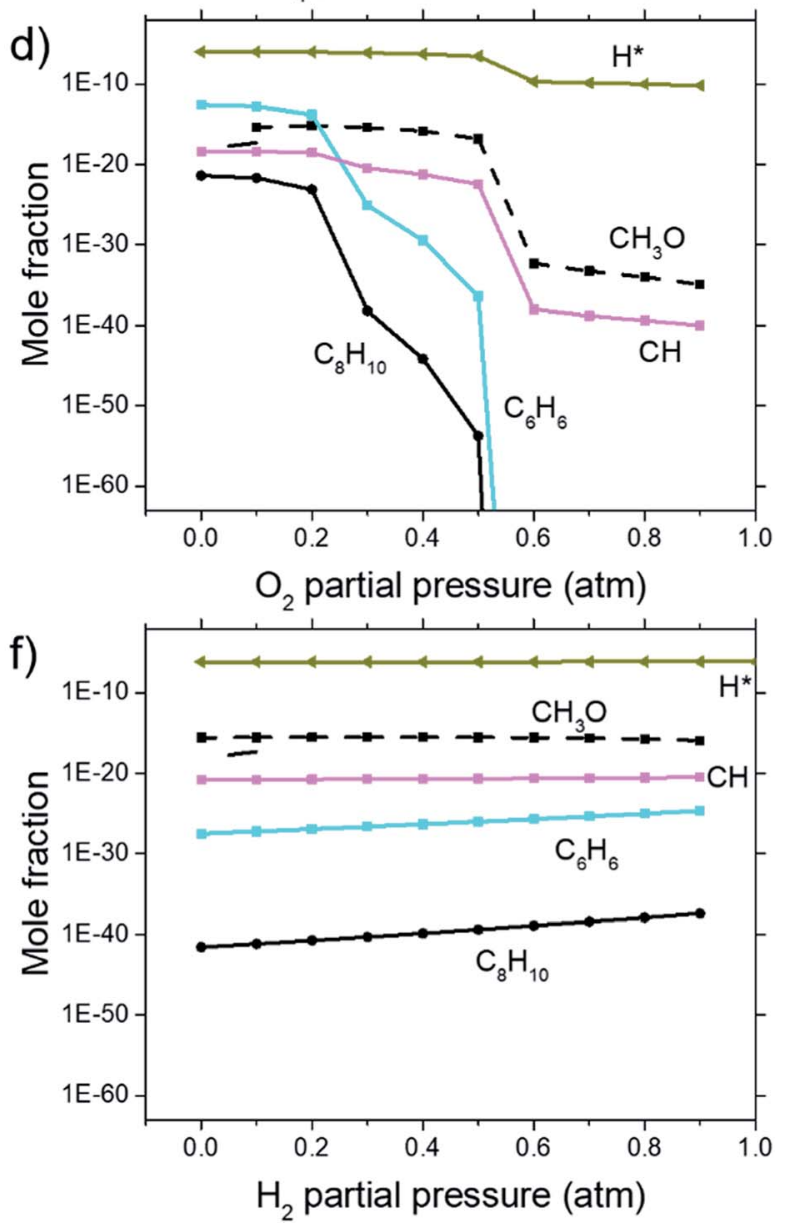

Fig. 7 Concentrations of equilibrium species as calculated by Cantera for dependencies on (a) \& (b) $\mathrm{CH}_{4}$ partial pressure, (c) \& (d) $\mathrm{O}_{2}$ partial pressure, and (e) $\&(f) \mathrm{H}_{2}$ partial pressure. Calculations were performed at $1000{ }^{\circ} \mathrm{C}$ at $1 \mathrm{~atm}$. (b), (d), and (f) shows species with lower concentrations not shown in (a), (c), and (e).

itself. Overall, we could conclude that the deposit obtained contains amorphous carbon, multilayer polycrystalline graphene as well as diamond-like carbon.

\section{Chemical equilibrium analysis}

Calculations for the concentration of equilibrium species for each dependency on $\mathrm{CH}_{4}, \mathrm{O}_{2}$, and $\mathrm{H}_{2}$ were performed using
Cantera. Focussing on the effects of changing $P\left(\mathrm{CH}_{4}\right)$, Fig. 7(a) and (b) shows that combustion products of hydrocarbon such as $\mathrm{H}_{2} \mathrm{O}, \mathrm{CO}_{2}, \mathrm{CO}$, and $\mathrm{CH}_{3} \mathrm{O}$ reach a peak at around $P\left(\mathrm{CH}_{4}\right)=0.5$ atm and declines with higher $P\left(\mathrm{CH}_{4}\right)$ since there is less $\mathrm{O}_{2}$ available. Formation of complex hydrocarbons $\left(\mathrm{C}_{6} \mathrm{H}_{6}\right.$ and $\left.\mathrm{C}_{8} \mathrm{H}_{10}\right), \mathrm{H}_{2}$ and $\mathrm{H}^{*}$ radical undergoes a sharp increase as it transitions from a fuel lean mixture to a fuel rich mixture at 

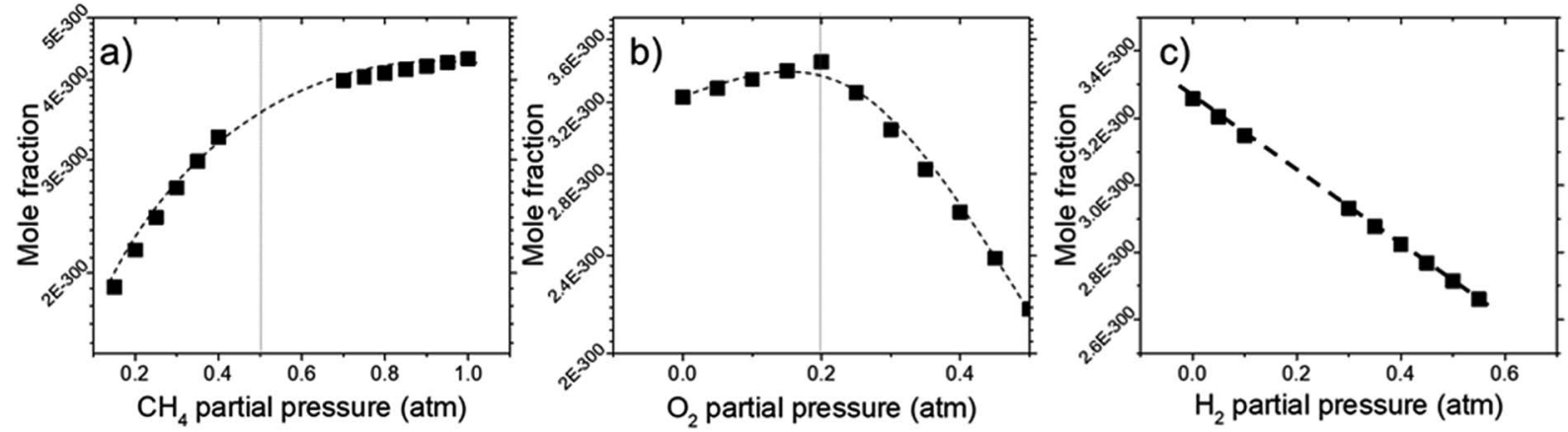

Fig. 8 Concentrations of equilibrium species for BIN2OJ as calculated by Cantera for dependencies on (a) $\mathrm{CH}_{4}$, (b) $\mathrm{O}_{2}$, and (c) $\mathrm{H}_{2}$ partial pressure. Calculations were performed at $1000{ }^{\circ} \mathrm{C}$ at $1 \mathrm{~atm}$.

a)

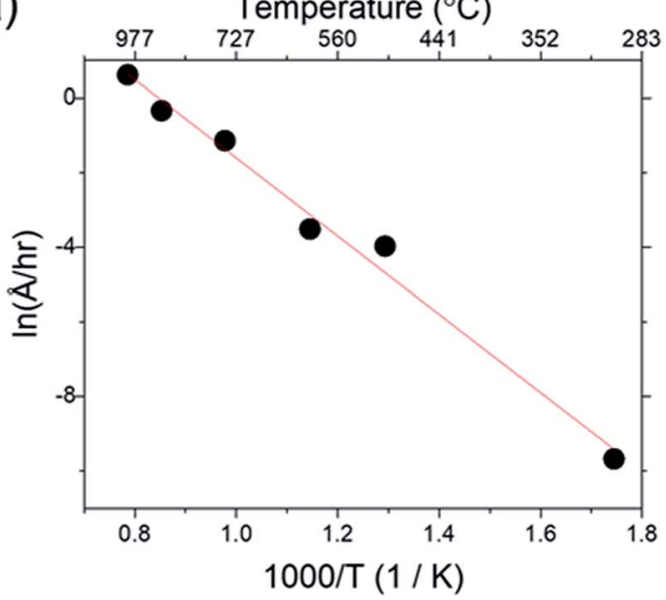

b)

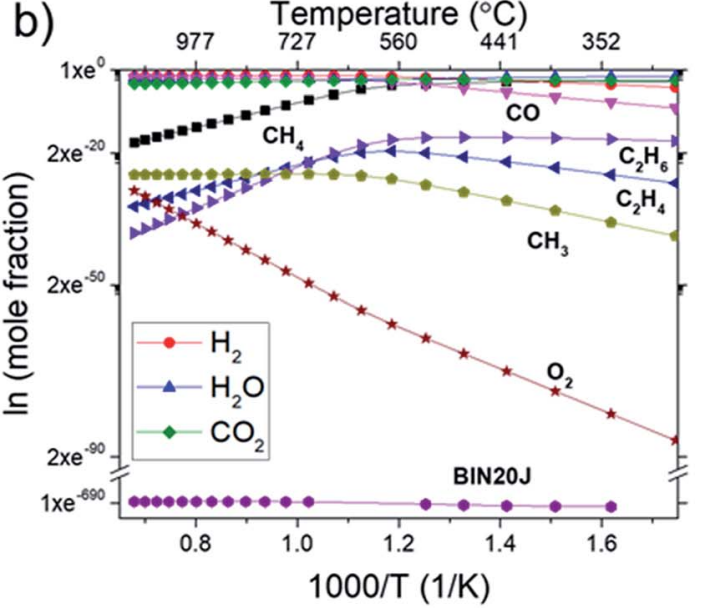

Fig. 9 (a) Arrhenius plot for graphene growth rate calculated from sheet resistance and (b) van't Hoff plot of various species as calculated by Cantera. Calculations were performed at $1000^{\circ} \mathrm{C}$ at $1 \mathrm{~atm}$.

$P\left(\mathrm{CH}_{4}\right)=0.2$ atm. At higher concentrations, hydrocarbon species also increases but slow down after about $P\left(\mathrm{CH}_{4}\right)=0.5$ atm. The growth rate of graphene observed in Fig. 3(a) and 4 also mimics this trend.

Comparisons between dependency of graphene thickness on $P\left(\mathrm{O}_{2}\right)$ and its equilibrium species concentration do not present any notable similarities. However, as expected, Fig. 7(c) and (d) shows a drastic reduction of hydrocarbon and hydrogen species at $P\left(\mathrm{O}_{2}\right)>0.5$ atm as the gas composition turns into a fuel-lean mixture. Also, the point $P\left(\mathrm{O}_{2}\right)=0.2$ atm where deposit thickness was highest was also the point where most hydrocarbons undergo a sharp decline in equilibrium concentration as $\mathrm{O}_{2}$ increases. Judging from the increased concentration of combustion products, oxidation reactions are the cause for this. Whereas according to Fig. 7(e) and (f), concentrations of hydrocarbon species increases at higher $P\left(\mathrm{H}_{2}\right)$ even as initial $\mathrm{CH}_{4}$ gets reduced due to Le Chatelier's principle to counter the increased $P\left(\mathrm{H}_{2}\right)$. Deposit thickness in Fig. 3(c) was also shown to increase at higher $P\left(\mathrm{H}_{2}\right)$. Regardless, equilibrium species considered here does not closely follow the changes in deposition thickness from experiments. It is probable that there are other species that have a better correlation to our experimental data.

In order to find the chemical species vital for graphene growth, each species available in the model was evaluated. From all the species contained within the mechanism, it was found that a chemical species $\mathrm{C}_{12972032} \mathrm{H}_{1622016}$ (codename: BIN20J) is a possible candidate as it possesses the best correlation to our experimentally obtained data as shown in Fig. 8. Judging from the $\mathrm{H} / \mathrm{C}$ atomic ratio of 0.125 for this species, we believe this gives the closest approximation available in the model to the deposit thickness obtained experimentally.

The equilibrium concentration for BIN20J displays a direct correlation to deposit thickness for $P\left(\mathrm{CH}_{4}\right)$ and $P\left(\mathrm{O}_{2}\right)$ in Fig. 8(a) and (b). Analysis of reaction order shown in Fig. $\mathrm{S} 2 \uparrow$ also shows that growth rate is a $1^{\text {st }}$ order reaction which explains the close correlation of BIN20J concentration to deposit thickness. Calculations on the yield and selectivity of BIN20J was also done (Fig. S3 $\dagger$ ), it shows decreasing yield and selectivity as $P\left(\mathrm{CH}_{4}\right)$ increases as more hydrocarbon by-products are also produced at higher methane concentration. Selectivity for BIN20J increases above $P\left(\mathrm{O}_{2}\right)=0.2 \mathrm{~atm}$ but its yield reaches a plateau at that point. This is believed to be due to its consumption by excess oxygen despite its increased selectivity. Changes to deposit thickness in relation to $P\left(\mathrm{H}_{2}\right)$ shows poor correlation to the predicted values of BIN20J. However as noted previously, changes in deposit thickness due to $\mathrm{H}_{2}$ dependency were an 
Table 1 Reported activation energies of graphene growth and related reactions

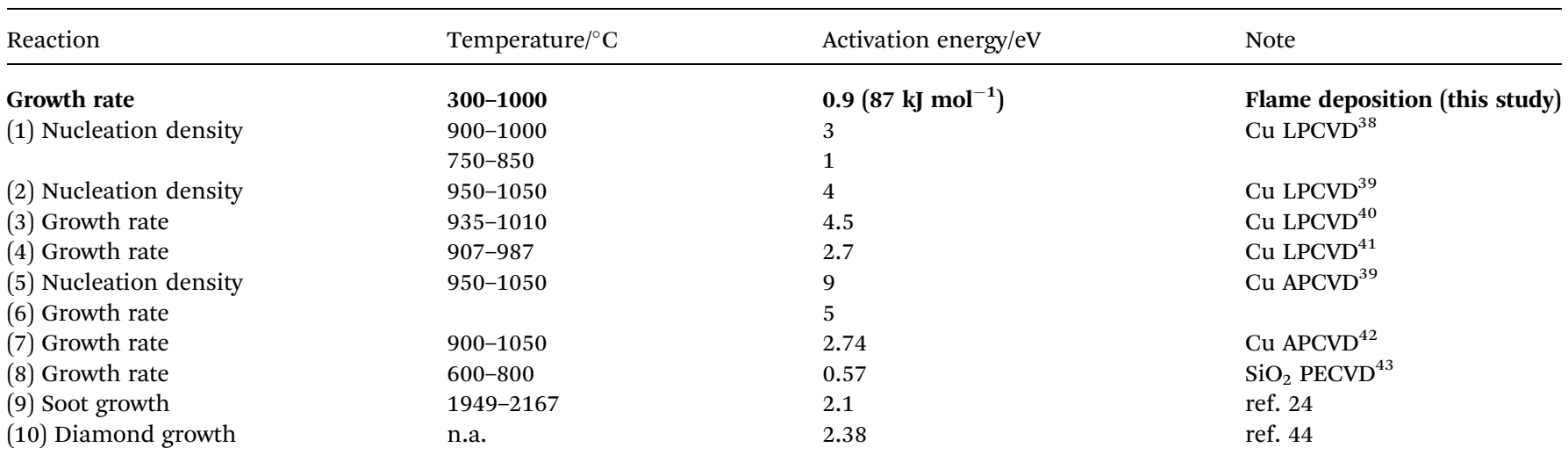

order of magnitude smaller than those due to $\mathrm{CH}_{4}$ and $\mathrm{O}_{2}$. Studies have noted that graphene could still be obtained by flame deposition even without $\mathrm{H}_{2}$ gas being used ${ }^{28}$ and chemisorbed hydrogen on $\mathrm{Cu}$ functions as a catalyst for $\mathrm{CH}_{4}$ heterogenous dissociation on $\mathrm{Cu}^{29}$ From this, we believe that $\mathrm{H}_{2}$ has a small influence in gas phase kinetics and instead has a bigger role in affecting the substrate itself directly. Since the model involves only gas phase reactions, such heterogeneous reactions are left unaccounted for thus leading to the inconsistency between experimental and predicted model. Regardless, the predicted values of BIN20J has been shown to have a good correlation to experimental data.

The close correlation found between experimental values of deposit thickness and equilibrium concentration of BIN20J was further evaluated by Arrhenius and van't Hoff analysis. Both are useful tools in understanding reaction kinetics. ${ }^{30}$ An Arrhenius plot (eqn (2)) of rate constant, $k$ against the temperature reciprocal, $1 / T$ as well as equilibrium constant, $K_{\text {eq }}$ against $1 / T$ of the van't Hoff equation (eqn (3)) gives useful information on the reaction mechanism.

$$
\ln k=-\frac{E_{\mathrm{a}}}{R T}+\ln A
$$

$k$ : reaction rate constant, $E_{\mathrm{a}}$ : activation energy, $R$ : gas constant, $T$ : temperature, $A$ : pre-exponential factor.

$$
\ln K_{\mathrm{eq}}=-\frac{\Delta H}{R T}+\frac{\Delta S}{R}
$$

$K_{\text {eq }}$ : equilibrium constant, $\Delta H$ : enthalpy energy, $R$ : gas constant, $T$ : temperature, $\Delta S$ : entropy energy.

In Fig. 9(a), Arrhenius plot of graphene growth rate shows that a single mechanism dominates across the temperature range of $300{ }^{\circ} \mathrm{C}$ to $1000{ }^{\circ} \mathrm{C}$. The van't Hoff plot in Fig. 9(b), however, shows that only BIN20J has a single reaction mechanism responsible for its production within the same temperature range. Other species have 2 distinct kinetic regimes involved in its production which has a transition at around $600{ }^{\circ} \mathrm{C}$. As an example, formation of $\mathrm{C}_{2} \mathrm{H}_{4}$ was shown to be endothermic at lower temperatures but exothermic at higher temperatures indicating a change in reaction mechanism. Experimentally, gas phase analysis during methane combustion also shows this mechanism transition ${ }^{31}$ which was corroborated by numerical analysis. ${ }^{32}$ The transition as temperature was increased beyond $600{ }^{\circ} \mathrm{C}$ was attributed to the mass transport as being the limiting step at such accelerated reaction rates. The fact that BIN20J remains linear could be due to it being a heavier hydrocarbon (i.e. soot particles) that is less affected to the gas phase kinetics.

The calculated activation energy of our deposition reaction was $0.9 \mathrm{eV}\left(87 \mathrm{~kJ} \mathrm{~mol}^{-1}\right)$ which is markedly lower than graphene grown by conventional CVD methods as seen in Table $1, \# 1$. In a typical LPCVD, the rate-limiting step for graphene was determined to be the dissociation of adsorbed $\mathrm{CH}_{4}$ as determined by $a b$ initio studies ${ }^{33}$ and mass transport is responsible for the ratelimiting step at APCVD ${ }^{34,35}$ which generally leads to an increased energy barrier (Table 1, \#1-\#7). Only through the use of PECVD, activation energy lower than our flame deposition method was achievable (Table 1, \#8). Also, most reported activation energies for conventionally grown CVD graphene has 2 separate $E_{\mathrm{a}}$ which infers 2 separate kinetic regimes for graphene growth (Table 1, $\# 1$ ). Additionally, $\mathrm{CH}_{4}$ combustion was also reported to have 2 distinct mechanisms, a slow reaction and ignition depending on the temperature. ${ }^{36,37}$ Also, due to the nature of this method being of a combustion reaction, soot production (Table 1, \#9) and diamond formation (Table 1, \#10) was also considered but it was found to have very different activation energies. In contrast, flame deposition only shows a single mechanism from the Arrhenius plot which means graphene grows by a different mechanism path which is also unique from diamond and soot formation.

While a thorough understanding of the growth mechanism of graphene by flame deposition still eludes us, our results provides certain insights on the growth of graphene by flame deposition. First, graphene growth follows closely with the BIN20J formation using a soot formation mechanism reported by Ergut $e t a l .{ }^{21}$ In this case, BIN20J formation in the gas phase begins from decomposition of $\mathrm{CH}_{4}$ into $\mathrm{CH}_{3}$ which then undergoes various recombination reaction to form heavier hydrocarbon leading to BIN20J. Second, the big difference in reported activation energies of graphene growth by CVD eliminates such mechanism that involves heterogeneous decomposition of $\mathrm{CH}_{4}$ on $\mathrm{Cu}$ and those of soot or diamond formation. From the formation of BIN20J, it will then adsorb on $\mathrm{Cu}$ 
substrate to provide a nucleation point for graphene growth. At this point, how BIN20J develops into graphene is unclear but we believe that it might proceed through $\mathrm{CH}_{4}$ decomposition promoted by adsorbed oxygen since it possesses activation energy $(0.9 \mathrm{eV})$ closest to our experimental values. ${ }^{45,46}$

\section{Conclusions}

An experimental flame deposition setup has been built for the growth of few-layer graphene. Raman analysis shows multilayer graphene with a monolayer ratio $\left(I_{2 \mathrm{D}} / I_{\mathrm{G}}\right)$ of 0.65 and defect ratio $\left(I_{\mathrm{D}} / I_{\mathrm{G}}\right)$ of 0.58 which was comparable to literature. We also show that numerical analysis by an open source software using an appropriate mechanism model provides a close prediction to the actual graphene deposition. Changes to deposit thickness when $\mathrm{CH}_{4}$ and $\mathrm{O}_{2}$ were varied was found to agree with simulated values for BIN20J. Deviations between experimental and simulation results for $P\left(\mathrm{H}_{2}\right)$ suggests $\mathrm{H}_{2}$ has a minor role in gas phase kinetics and influences the heterogeneous reaction on the substrate which is not accounted for by the mechanism file used. At this current stage only the gas phase mechanism was considered but with proper improvements, a model that could predict the actual deposition is certainly possible. Considerations of the growth kinetics lead us to believe that the growth mechanism includes the gas phase formation of BIN20J followed by its adsorption on $\mathrm{Cu}$ substrate which then grows into graphene.

\section{Conflicts of interest}

There are no conflicts to declare.

\section{Acknowledgements}

This research was financially supported by Ministry of Higher Education, Malaysia with Grant Number LRGS15-003-0004 and FRGS17-035-0601. We also express our gratitude to Assoc. Prof. Sannomiya Takumi of Tokyo Institute of Technology for support and fruitful discussions on TEM.

\section{Notes and references}

1 K. S. Novoselov, V. I. Fal'ko, L. Colombo, P. R. Gellert, M. G. Schwab and K. Kim, Nature, 2012, 490, 192-200.

2 X. Li, W. Cai, I. H. Jung, J. H. An, D. Yang, A. Velamakanni, R. Piner, L. Colombo and R. S. Ruoff, ECS Trans., 2009, 19, 41-52.

3 S. Bae, H. Kim, Y. Lee, X. Xu, J.-S. Park, Y. Zheng, J. Balakrishnan, T. Lei, H. Ri Kim, Y. Il Song, Y.-J. Kim, K. S. Kim, B. Özyilmaz, J.-H. Ahn, B. H. Hong and S. Iijima, Nat. Nanotechnol., 2010, 5, 574-578.

4 J.-H. H. Chen, C. Jang, S. Xiao, M. Ishigami and M. S. Fuhrer, Nat. Nanotechnol., 2008, 3, 206-209.

5 K. S. Novoselov, A. K. Geim, S. V. Morozov, D. Jiang, Y. Zhang, S. V. Dubonos, I. V. Grigorieva and A. A. Firsov, Science, 2004, 306, 666-669.
6 X. Wang, Q. Yuan, J. Li and F. Ding, Nanoscale, 2017, 9, 11584-11589.

7 H. Sugime, L. D'Arsié, S. Esconjauregui, G. Zhong, X. Wu, E. Hildebrandt, H. Sezen, M. Amati, L. Gregoratti, R. S. Weatherup and J. Robertson, Nanoscale, 2017, 9, 14467-14475.

8 J. Fujita, T. Hiyama, A. Hirukawa, T. Kondo, J. Nakamura, S. Ito, R. Araki, Y. Ito, M. Takeguchi and W. W. Pai, Sci. Rep., 2017, 7, 12371.

9 D. A. Boyd, W.-H. Lin, C.-C. Hsu, M. L. Teague, C.-C. Chen, Y.-Y. Lo, W.-Y. Chan, W.-B. Su, T.-C. Cheng, C.-S. Chang, C.-I. Wu and N.-C. Yeh, Nat. Commun., 2015, 6, 6620.

10 A. Khalid, M. A. Mohamed and A. A. Umar, Sains Malays., 2017, 46, 1111-1117.

11 J. V. Busch and J. P. Dismukes, Diamond Relat. Mater., 1994, 3, 295-302.

12 R. L. Vander Wal, T. M. Ticich and V. E. Curtis, Chem. Phys. Lett., 2000, 323, 217-223.

13 Z. Li, H. Zhu, D. Xie, K. Wang, A. Cao, J. Wei, X. Li, L. Fan and D. Wu, Chem. Commun., 2011, 47, 3520.

14 Z. Li, H. Zhu, K. Wang, J. Wei, X. Gui, X. Li, C. Li, L. Fan, P. Sun and D. Wu, Carbon, 2011, 49, 237-241.

15 B. M. Kellie, A. C. Silleck, K. Bellman, R. Snodgrass and S. Prakash, RSC Adv., 2013, 3, 7100.

16 N. K. Memon, S. D. Tse, J. F. Al-Sharab, H. Yamaguchi, A.-M. B. Goncalves, B. H. Kear, Y. Jaluria, E. Y. Andrei and M. Chhowalla, Carbon, 2011, 49, 5064-5070.

17 E. Ismail, M. S. Sirat, A. M. Abdul Hamid, R. Othman, M. A. A. Mohd Abid and M. H. Ani, Sains Malays., 2017, 46, 1011-1016.

18 M. H. Ani, M. A. Kamarudin, A. H. Ramlan, E. Ismail, M. S. Sirat, M. A. Mohamed and M. A. A. Mohd Abid, J. Mater. Sci., 2018, 53, 7095-7111.

19 D. G. Goodwin, N. G. Glumac and H. S. Shin, Proc. Combust. Inst., 1996, 26, 1817-1824.

20 D. G. Goodwin, N. G. Glumac and E. J. Corat, in Laser Techniques for State-Selected and State-to-State Chemistry II, ed. J. W. Hepburn, 1994, vol. 2124, pp. 292-298.

21 A. Ergut, S. Granata, J. Jordan, J. Carlson, J. B. Howard, H. Richter and Y. A. Levendis, Combust. Flame, 2006, 144, 757-772.

22 J. Schindelin, I. Arganda-Carreras, E. Frise, V. Kaynig, M. Longair, T. Pietzsch, S. Preibisch, C. Rueden, S. Saalfeld, B. Schmid, J.-Y. Tinevez, D. J. White, V. Hartenstein, K. Eliceiri, P. Tomancak and A. Cardona, Nat. Methods, 2012, 9, 676-682.

23 D. G. Goodwin, H. K. Moffat and R. L. Speth, http:// www.cantera.org, DOI: 10.5281/zenodo.170284.

24 Ö. L. Gülder, Combust. Flame, 1995, 101, 302-310.

25 J. C. Meyer, A. K. Geim, M. I. Katsnelson, K. S. Novoselov, T. J. Booth and S. Roth, Nature, 2007, 446, 60-63.

26 Y. Wang, D. C. Alsmeyer and R. L. McCreery, Chem. Mater., 1990, 2, 557-563.

27 M. E. Kozlov, K. Yase, N. Minami, P. Fons, H.-A. Durand, A. N. Obraztsov, K. Nozaki and M. Tokumoto, J. Phys. D: Appl. Phys., 1996, 29, 929-933. 
28 N. K. Memon, S. D. Tse, M. Chhowalla and B. H. Kear, Proc. Combust. Inst., 2013, 34, 2163-2170.

29 I. Vlassiouk, M. Regmi, P. Fulvio, S. Dai, P. Datskos, G. Eres and S. Smirnov, ACS Nano, 2011, 5, 6069-6076.

30 R. C. Flagan and J. H. Seinfeld, Fundamentals of air pollution engineering, Prentice Hall, 1988.

31 T. A. Griffin and L. D. Pfefferle, AIChE J., 1990, 36, 861-870.

32 Y. Peng, Z. Jiang and J. Chen, J. Phys. Chem. A, 2017, 121, 2209-2220.

33 Y. Shibuta, R. Arifin, K. Shimamura, T. Oguri, F. Shimojo and S. Yamaguchi, Chem. Phys. Lett., 2014, 610-611, 33-38.

34 G. Li, S.-H. Huang and Z. Li, Phys. Chem. Chem. Phys., 2015, 17, 22832-22836.

35 F. B. Fauzi, E. Ismail, M. H. Ani, S. N. Syed Abu Bakar, M. A. Mohamed, B. Y. Majlis, M. F. Md Din and M. A. Azam Mohd Abid, J. Mater. Res., 2018, 33, 1308.

$36 \mathrm{H}$. Vandenabeele, R. Corbeels and A. van Tiggelen, Combust. Flame, 1960, 4, 253-260.

37 R. G. W. Norrish and S. G. Foord, Proc. R. Soc. A, 1936, 157, 503-525.
38 H. Kim, C. Mattevi, M. R. Calvo, J. C. Oberg, L. Artiglia, S. Agnoli, C. F. Hirjibehedin, M. Chhowalla and E. Saiz, ACS Nano, 2012, 6, 3614-3623.

39 I. Vlassiouk, S. Smirnov, M. Regmi, S. P. Surwade, N. Srivastava, R. Feenstra, G. Eres, C. Parish, N. Lavrik, P. Datskos, S. Dai and P. Fulvio, J. Phys. Chem. C, 2013, 117, 18919-18926.

40 J. Kraus, L. Böbel, G. Zwaschka and S. Günther, Ann. Phys., 2017, 529, 1700029.

41 T. Terasawa and K. Saiki, Nat. Commun., 2015, 6, 6834.

42 S. Xing, W. Wu, Y. Wang, J. Bao and S.-S. S. Pei, Chem. Phys. Lett., 2013, 580, 62-66.

43 S. Ghosh, S. R. Polaki, N. Kumar, S. Amirthapandian, M. Kamruddin and K. Ostrikov, Beilstein J. Nanotechnol., 2017, 8, 1658-1670.

44 J. J. Gracio, Q. H. Fan and J. C. Madaleno, J. Phys. D: Appl. Phys., 2010, 43, 374017.

45 J. Wang and G.-C. Wang, J. Phys. Chem. C, 2018, 122, 1733817346.

46 T. Niu, Z. Jiang, Y. Zhu, G. Zhou, M. A. van Spronsen, S. A. Tenney, J. A. Boscoboinik and D. Stacchiola, J. Phys. Chem. B, 2018, 122, 855-863. 